\title{
Macrophage-tropic Variants Initiate Human Immunodeficiency Virus Type 1 Infection after Sexual, Parenteral, and Vertical Transmission
}

\author{
Angélique B. van’t Wout, ${ }^{\star}$ Neeltje A. Kootstra, ${ }^{\circ}$ Greetje A. Mulder-Kampinga, ${ }^{\ddagger}$ Nel Albrecht-van Lent,' \\ Henriëtte J. Scherpbier, "II Jan Veenstra,' Kees Boer, Roel A. Coutinho,' Frank Miedema," and Hanneke Schuitemaker* \\ * Department of Clinical Viro-Immunology, Central Laboratory of the Netherlands Red Cross Blood Transfusion Service and the \\ Laboratory of Experimental and Clinical Immunology of the University of Amsterdam, ${ }^{\ddagger}$ Department of Virology, ${ }^{11}$ Department of \\ Neonatology, Gynaecology and Obstetrics, and ${ }^{\| 1}$ Department of Paediatrics, Academic Medical Centre, and Municipal Health Service, \\ Amsterdam, The Netherlands
}

\begin{abstract}
Macrophage-tropic, non-syncytium-inducing, HIV-1 variants predominate in the asymptomatic phase of infection and may be responsible for establishing infection in an individual exposed to the mixture of HIV-1 variants. Here, genotypical and phenotypical characteristics of virus populations, present in sexual, parenteral, or vertical donor-recipient pairs, were studied. Sequence analysis of the V3 domain confirmed the presence of a homogeneous virus population in recently infected individuals. Biological HIV-1 clones were further characterized for syncytium inducing capacity on the MT2 cell line and for macrophage tropism as defined by the appearance of proviral DNA upon inoculation of monocyte-derived macrophages. Both sexual and parenteral transmission cases revealed a selective outgrowth in the recipient of the most macrophage-tropic variant(s) present in the donor. In three out of five vertical transmission cases, more than one highly macrophage-tropic virus variant was present in the child shortly after birth, suggestive of transmission of multiple variants. In three primary infection cases, homogeneous virus populations of macrophagetropic, non-syncytium-inducing variants were present prior to seroconversion, thus excluding humoral immunity as the selective pressure in favour of macrophage-tropic variants. These observations may have important implications for vaccine development. (J. Clin. Invest. 1994. 94:2060-2067.) Key words: human immunodeficiency virus type 1 phenotype - maternal transmission - monocyte - AIDS • primary infection
\end{abstract}

\section{Introduction}

Human immunodeficiency virus type I (HIV-1) isolates can display differences in biological properties such as syncytium

Address correspondence to Hanneke Schuitemaker, Dept. of Clinical Viro-immunology, Central Laboratory of the Netherlands, Red Cross Blood Transfusion Service, Plesmanlaan 125, 1066 CX Amsterdam, The Netherlands. 1994.

Received for publication 10 May 1994 and in revised form 14 July

J. Clin. Invest.

(c) The American Society for Clinical Investigation, Inc. 0021-9738/94/11/2060/08 \$2.00

Volume 94, November 1994, 2060-2067 inducing $(\mathrm{SI})^{1}$ capacity, replication rate, and cytotropism (15). T cell line-tropic SI HIV-1 variants appear during the asymptomatic phase of infection in about $50 \%$ of infected individuals and are associated with accelerated $\mathrm{CD} 4^{+}$cell decline and more rapid progression to AIDS (6). In contrast, in the early asymptomatic phase in general only non-syncytium-inducing (NSI) HIV-1 variants are present, which, unlike SI HIV-1 variants, are highly macrophage tropic (7). These macrophagetropic NSI variants persist during all stages of infection, even after the emergence of SI variants $(7,8)$, indicating their importance for viral persistence. The appearance of SI variants in later stages of infection in about half of the infected individuals would suggest the presence of SI variants in at least some individuals that may be involved in HIV-1 transmission. However, in more than $95 \%$ of recently HIV-1-infected individuals only NSI variants are detected $(5,9)$. It has been suggested that at the time of primary infection cotransmitted SI variants are immediately cleared from the body by the immune system, due to their high level of replication (10-12). In the described cases, however, this clearance was transient and may not explain the absence of SI variants in the majority of HIV-1-infected individuals.

Several groups have analyzed envelope sequences of virus populations present during primary infection. The identification of specific amino acid residues in the third variable domain (V3) of the HIV-1 envelope gp120 molecule as major determinants for SI capacity and macrophage tropism (13-15) provided the possibility for a biologically significant interpretation of available sequence data. The V3 sequences of HIV-1 variants present around the moment of seroconversion all show a remarkable homology with sequences that are characteristic for macrophage-tropic NSI viruses (16-18). In these studies the biological phenotype of HIV-1 clones was deduced from the sequence and was not tested in biological assays. However, the selection of macrophage-tropic or NSI variants upon sexual transmission has indeed been reported (19). In the present study we performed genotypical and phenotypical analyses of virus populations present in donor-recipient pairs between whom sexual, parenteral, or vertical transmission of HIV-1 was documented. Moreover, the clonal composition of HIV-1 populations present at the time of seroconversion following sexual transmission was studied.

\section{Methods}

Patients. From two homosexual couples, participating in the Amsterdam cohort studies of AIDS and between whom sexual transmission was

1. Abbreviations used in this paper: CTL, cytotoxic T lymphocyte; MDM, monocyte-derived macrophages; NSI, non-syncytium inducing; SC, seroconversion; SI, syncytium inducing; V3, third variable domain of the HIV-1 envelope gp120 molecule. 
documented, PBMC were isolated from donor and recipient around the time of seroconversion of the recipient. Both recipients had engaged in unprotected anal intercourse with their respective partners.

From two parenteral transmission cases PBMC were available from donor and recipient. In one case the recipient $\mathrm{HIV}_{\mathrm{Ams}} 127$ had been accidentally injected with a minute amount of blood from patient ACH704 who suffered from wasting syndrome CDC IVa (20). In the other case, a few milliliters of blood were deliberately transferred from an AIDS patient $\mathrm{HIV}_{\text {Ams }} 199$ to recipient ACH9012 (Veenstra et al., manuscript in preparation). PBMC were isolated from five motherchild pairs, that participate in the Dutch prospective study of HIVseropositive women and their children and between whom vertical transmission was documented. PBMC, isolated during pregnancy from the mother and after delivery from both mother and child, were used for analysis.

PBMC from three individuals (one heterosexual and two homosexual), who presented at the Academic Medical Centre with clinical symptoms of primary HIV-1 infection, were sampled frequently before and after seroconversion. All PBMC samples were cryopreserved before use except for PBMC from patient HIV Ams $_{199}$ that were used freshly.

Virus isolation. Isolation of biological virus clones was performed as described (8). Briefly, patient PBMC were cocultivated with 3-d PHA-stimulated PBMC from noninfected donors in 96-well plates. Fresh medium and PHA-stimulated healthy donor PBMC were added every week. Virus replication as reflected by the presence of HIV antigen in culture supernatant was determined by an in-house p24 antigen capture ELISA. SI capacity of the virus clones was determined by cocultivation with MT2 cells. After 4 wk PBMC and supernatant from each HIV1 positive culture were transferred to a T25 flask with $5 \times 10^{6} \mathrm{PHA}$ stimulated PBMC. When these cultures showed evidence for virus production, cells were frozen and $\sim 1 \times 10^{6}$ cells were used for isolation of DNA. HIV-1 positive supernatant from the PBMC cultures was stored at $-70^{\circ} \mathrm{C}$ until testing for macrophage-tropism by inoculation of monocyte-derived macrophages (MDM).

$P C R$ and sequence analysis. Total DNA from PBMC harboring the biological HIV-1 clones was isolated as described (21). V3 sequences were amplified by PCR as described (22). Products were purified with a Geneclean kit (BIO 101, Inc. Vista CA), and sequenced directly using the dideoxy chain termination method with Sequenase (USB, Cleveland, $\mathrm{OH})$, both according to instructions from the manufacturers.

Macrophage-tropism of HIV-1 clones. About $50 \%$ of primary HIV1 variants completely lack macrophage tropism $(7,23)$. These variants are restricted at an early step of the viral replication cycle, presumably entry (24). Their non-macrophage tropism is determined by the viral envelope $(25,26)$. The other $50 \%$ of primary isolates carry an envelope that, in principle, allows entry into macrophages. For establishment of productive infection, these variants show a variable dependency on cellular requirements that may vary between MDM derived from different donors (23). To minimize the influence of host cell restrictions, we used the presence of newly synthesized proviral DNA upon inoculation of MDM from two or more donors as a measure for macrophage-tropic envelopes.

Monocytes were obtained by centrifugal elutriation of Ficoll gradient-separated PBMC from blood donor volunteers and were plated at a concentration of $10^{6}$ cells per ml endotoxin-free Iscove's modified Dulbecco's medium containing $10 \%$ pooled human serum and cultured for $5 \mathrm{~d}$. Thus obtained MDM were then exposed to $0.2 \mathrm{ml}$ of virus stock, which had been DNaseI ( $200 \mathrm{ng} / \mathrm{ml}$ RQ1 DNase; Promega Biotec, Madison, WI) treated for $1 \mathrm{~h}$ at $37^{\circ} \mathrm{C}$ in medium containing $6 \mathrm{mM}$ $\mathrm{MgCl}_{2}$ and filtered through a $0.22-\mu \mathrm{m}$ filter. Before inoculation, part of the cells were incubated for $1 \mathrm{~h}$ at $37^{\circ} \mathrm{C}$ in the presence of $10 \mu \mathrm{M}$ zidovudine, which prevents reverse transcription, to discriminate newly synthesized DNA from DNA present in the inoculum. Virus stocks obtained from donor and recipient of each transmission couple had similar p24 contents. Cells were washed $1 \mathrm{~d}$ after inoculation and cultured for 6 more d. DNA was then extracted as described (21), amplified in a nested PCR amplifying the p24 region of gag (27), and reaction products were analyzed by agarose gel electrophoresis. No PCR prod- ucts were obtained from the zidovudine-treated controls. MDM from one to four seronegative blood donors were tested with each virus stock. For the analysis of macrophage tropism, MDM from the same blood donors were used for all the HIV-1 clones derived from one donorrecipient couple. Macrophage tropism of HIV-1 variants is defined as the percentage of MDM cultures that show evidence of proviral DNA: $0 \%,-; 1-25 \%, \pm ; 26-50 \%,+; 51-75 \%,++$; and $76-$ $100 \%,+++$.

\section{Results}

Clonal HIV-1 populations in donors and recipients of two homosexual transmission cases. From both donors and recipients in two homosexual transmission cases phenotype and genotype of clonal virus populations, present around the time point of seroconversion of the recipient, were analyzed. Biological clones, isolated on PHA-stimulated PBMC, were analyzed for SI capacity and macrophage-tropism and, in addition, V3 sequence analysis was performed. The results are depicted in Table I. From donor ACH486 both SI and NSI clones were obtained 3 and 12 mo after the seroconversion date of recipient ACH491. Virus clones with the SI phenotype constituted $76 \%$ of the total virus population at the 12-mo time point. From the recipient, only NSI clones were obtained. V3 loop sequence analysis was performed on seven SI and seven NSI clones from the donor and on two NSI clones from the recipient. These two NSI clones had identical V3 loop sequences (sequence 9) that showed highest homology to the NSI clones present in donor ACH486 (sequences 2, 3, 7, and 8). When tested for macrophage tropism on MDM from four different donors these NSI variants appeared to be the most macrophage-tropic virus variants present in the donor.

In the second homosexual transmission case only NSI HIV1 clones were obtained from both donor and recipient. The major variant present in donor ACH455 (sequence 1) was also detected in recipient ACH1140. When the HIV-1 clones from donor ACH455, representing three variants with genotypically distinct V3 domains, were tested for their macrophage-tropism, the virus clones with highest homology to the HIV-1 clone isolated from recipient ACH1140, most efficiently infected MDM from the four different donors tested.

Composition of $H I V-1$ populations in donors and recipients of two parenteral transmission cases. In the first parenteral transmission case, the recipient ( HIV $_{\text {Ams }} 127$ ) was exposed to a minute amount of blood from a patient (ACH704) with wasting syndrome CDC IVa (20). A total of 11 clones were obtained from the donor of which five clones had the SI and six clones had the NSI phenotype (Table II). All NSI clones were able to replicate in MDM to some extent, whereas only one of the SI clones (sequence 4) was macrophage-tropic. Interestingly, this macrophage-tropic SI clone was the only virus variant present upon infection of recipient $\mathrm{HIV}_{\text {Ams }} 127$, possibly due to the low inoculum size. Biological clones from recipient $\mathrm{HIV}_{\mathrm{Ams}} 127$ were obtained on PHA-stimulated PBL as well as on MDM (8). Both methods yielded clones with exactly the same V3 loop compatible with the presence of a clonal virus population. Shortly after seroconversion of the recipient all clones were macrophage-tropic, but after 5.5 mo none of the clones isolated on PHA-stimulated PBL were macrophage-tropic, possibly reflecting evolution to $\mathrm{T}$ cell-tropic viruses.

In the second parenteral transmission case, the recipient (ACH9012) was exposed to a few milliliters of blood from an 
Table I. Genotype and Phenotype of Biological Clones Obtained from Two Homosexual Donor-Recipient Pairs

\begin{tabular}{|c|c|c|c|c|c|c|c|c|c|c|c|}
\hline & \multirow[b]{2}{*}{ Case } & \multirow[b]{2}{*}{$\begin{array}{c}\text { Mo after SC } \\
\text { recipient }\end{array}$} & \multirow[b]{2}{*}{ No. } & \multirow[b]{2}{*}{$\begin{array}{l}\text { V3 consensus } \\
\text { CTRPNNNTRKSIHIGPGRAFYTTGEI IGDIRQAHC }\end{array}$} & \multirow[b]{2}{*}{$n$} & \multirow[b]{2}{*}{$\mathrm{SI}^{8}$} & \multicolumn{5}{|c|}{ Macrophage tropism* } \\
\hline & & & & & & & A & B & C & D & Classification $^{*}$ \\
\hline \multirow[t]{8}{*}{ D } & $\mathrm{ACH}$ & 3 & 1 & $----G---K R--Y-------H--D R--------$ & 1 & + & nt & nt & 0 & 0 & - \\
\hline & 486 & & 2 & $----G----R--P----K--F--, Q---------$ & 2 & - & nt & nt & 2 & 2 & +++ \\
\hline & & & 3 & $----G----R--P----K V-F--.,---------$ & 1 & - & nt & nt & 1 & 1 & +++ \\
\hline & & 12 & 4 & $----\mathrm{G}---\mathrm{KR}--\mathrm{Y}-------\mathrm{H}--\mathrm{DR}-----\mathrm{K}---$ & 1 & + & 0 & 0 & 0 & 0 & - \\
\hline & & & 5 & $----G---K R--Y-------H--D R------R---$ & 3 & + & 0 & 1 & 1 & 0 & \pm \\
\hline & & & 6 & $----G---K R--Y-------Q--D R------R---$ & 2 & + & 1 & 0 & 0 & 0 & \pm \\
\hline & & & 7 & $----\mathrm{G}---\mathrm{KR}--\mathrm{P}----\mathrm{KV}-\mathrm{F}--.,-------$ & 2 & - & 2 & 1 & 0 & 0 & + \\
\hline & & & 8 & $----\mathrm{G}---\mathrm{KR}--\mathrm{P}----\mathrm{K}--\mathrm{F}--.,--------$ & 2 & - & 2 & 1 & 2 & 0 & ++ \\
\hline $\mathbf{R}$ & $\begin{array}{r}\mathrm{ACH} \\
491\end{array}$ & 0 & 9 & $----G----R--P----K--F--,---------$ & 2 & - & 2 & 0 & 2 & 2 & ++ \\
\hline \multirow[t]{3}{*}{ D } & $\mathrm{ACH}$ & -5 & 1 & 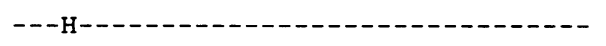 & 5 & - & 5 & 5 & 2 & 3 & ++ \\
\hline & 455 & & 2 & 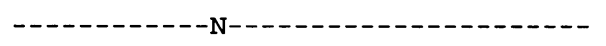 & 4 & - & 3 & 2 & 1 & 2 & + \\
\hline & & & 3 & 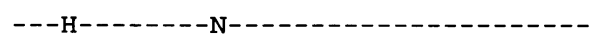 & 1 & - & 1 & 0 & 1 & 1 & ++ \\
\hline $\mathbf{R}$ & $\begin{array}{c}\mathrm{ACH} \\
1140\end{array}$ & 1 & 1 & $--\mathrm{H}-\mathrm{-}-\mathrm{C}-\mathrm{C}-\mathrm{C}-\mathrm{C}$ & 1 & - & 1 & 0 & 0 & 0 & \pm \\
\hline
\end{tabular}

$S C$, seroconversion; $D$, donor; $R$, recipient; no., sequence number; $n$, number of clones; ${ }^{8}$ SI phenotype was determined by cocultivation with the MT2 cell line, * Number of macrophagetropic clones from the total number of clones with that particular V3 loop, each column represents results obtained with MDM from one blood donor $A, B, C$, and $D .{ }^{\ddagger}$ As defined in Methods; nt, not tested.

Table II. Genotype and Phenotype of Biological Clones Obtained from Two Parenteral Donor-Recipient Pairs

\begin{tabular}{|c|c|c|c|c|c|c|c|c|c|}
\hline & \multirow[b]{2}{*}{ Case } & \multirow{2}{*}{$\begin{array}{l}\text { Mo after } \\
\text { exposure } \\
\text { recipient }\end{array}$} & \multirow[b]{2}{*}{ No. } & \multirow{2}{*}{$\begin{array}{l}\text { V3 consensus } \\
\text { CTRPNNNTRKSIHIGPGRAFYTTGEI IGDIRQAHC }\end{array}$} & \multirow[b]{2}{*}{$n$} & \multirow[b]{2}{*}{$\mathrm{SI}^{*}$} & \multicolumn{3}{|c|}{ Macrophage tropism ${ }^{\ddagger}$} \\
\hline & & & & & & & $\mathrm{E}$ & $\mathbf{F}$ & Classification $^{8}$ \\
\hline \multirow[t]{5}{*}{ D } & $\mathrm{ACH}$ & -8.0 & 1 & 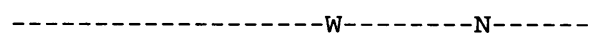 & 5 & - & 2 & 2 & + \\
\hline & 704 & & 2 & 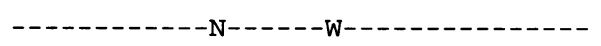 & 1 & - & 1 & 0 & + \\
\hline & & & 3 & ------- RVTM----VW------- & 2 & + & 0 & 0 & - \\
\hline & & & 4 & -------- RVTM----VW--------N-K---- & 2 & + & 0 & 1 & \pm \\
\hline & & & 5 & -------- RVTM----VW----V---N------ & 1 & + & 0 & 0 & - \\
\hline \multirow[t]{4}{*}{$\mathbf{R}$} & Ams & 1.5 & 4 & $---------R V T M----V W--------N-K----$ & $4^{p}$ & + & 3 & 2 & ++ \\
\hline & 127 & & 4 & -------- RVTM----VW-- - - - - N-K--- & $6^{\mathrm{m}}$ & + & 6 & 6 & +++ \\
\hline & & 5.5 & 4 & --------- RVTM----VW--------N-K--- & $4^{p}$ & + & 0 & 0 & - \\
\hline & & & 4 & ------- RVTM----VW------- $-\mathrm{N}-\mathrm{K}----$ & $3^{\mathrm{m}}$ & + & 3 & 3 & +++ \\
\hline \multirow[t]{6}{*}{ D } & Ams & 4.5 & 1 & $---------G---------A--D--------$ & 9 & - & 2 & 1 & \pm \\
\hline & 199 & & 2 & $---------G------S---A--D---------$ & 3 & - & 1 & 2 & + \\
\hline & & & 3 & $--------G------K---A--D--------$ & 2 & - & 0 & 0 & - \\
\hline & & & 4 & $--------G-------$ FA- $-D-------$ & 1 & - & 0 & 0 & - \\
\hline & & & 5 & $-----Y---$ G-R------V-AAEK-------- & 9 & + & 2 & 5 & + \\
\hline & & & 6 & $------G-R---$ S-VIA-EK------- & 3 & + & 2 & 3 & +++ \\
\hline \multirow[t]{4}{*}{$\mathbf{R}$} & $\mathrm{ACH}$ & 3.5 & 1 & $---------G---------A--D---------$ & 29 & - & 17 & 18 & ++ \\
\hline & 9012 & & 5 & $-----Y---$ G-R------V-AAEK-------- & 2 & + & 2 & 2 & +++ \\
\hline & & & 7 & $----Y---G-R-----$ VIA-EK-------- & 2 & + & 2 & 2 & +++ \\
\hline & & & 8 & -------- G-R------V-A-EK-------- & 1 & + & 1 & 0 & + \\
\hline
\end{tabular}

$D$, donor; $R$, recipient; No., sequence number; $n$, number of clones; ${ }^{\mathrm{P}}$ isolated on PHA-stimulated PBMC; ${ }^{\mathrm{m}}$ isolated on MDM; ${ }^{*}$ SI phenotype was determined by cocultivation with the MT2 cell line; ${ }^{\ddagger}$ Number of macrophagetropic clones from the total number of clones with that particular V3 loop. Each column represents results obtained with MDM from one blood donor $E, F .{ }^{\S}$ As defined in Methods. 
AIDS patient (HIV $\left.{ }_{\text {Ams }} 199\right)$. In this case several of the donor's virus variants, both SI and NSI, were transmitted (Table II). In the recipient a majority of highly macrophage-tropic HIV-1 clones and a selective expansion of NSI clones was observed; 19 out of 34 clones $(56 \%)$ in the donor had the NSI phenotype, whereas in the recipient 31 out of $36(86 \%)$ were NSI. The absence of immune control in the donor, who was diagnosed for AIDS already at the moment of transmission, may have allowed more diversification of the virus population.

Clonal HIV-1 populations in mothers and children involved in vertical transmission. Five mother-child pairs (Table III), between whom HIV-1 transmission was documented, were studied. In pair 114 intrauterine transmission was proven, based on the presence of virus in umbilical cord blood samples, where contamination with maternal blood could be ruled out (28). The time point of transmission in the other four cases is unknown. From all mothers and their children only HIV-1 clones with NSI phenotype and genotype were obtained. Shortly after birth the vast majority of virus clones detected in the children were highly macrophage tropic. In four out of five mothers, clones with certain V3 loop variants were not able to replicate in MDM of at least one of two donors tested. In two cases a minor variant of the mother (sequence 4 in M102 and sequence 5 in M137) seemed to have initiated infection in the child. The virus transmitted in pair 102 (sequence 4) was the minor one of two highly macrophage-tropic variants present in the mother $2 \mathrm{wk}$ before delivery. The other three variants detected at that time point were less macrophage-tropic. The virus transmitted in pair 137 (sequence 5) was the major variant of three highly macrophagetropic variants (sequences 5, 6, and 7) present in the mother 9.5 mo after delivery, but not 1.5 mo before delivery.

In three cases $(114,127$, and 133), several variants present in the children were also detected in their mothers before delivery, suggestive of transmission of multiple clones. All variants present in M127 2 wk before delivery were detected in child C127, either in PBMC obtained 10.5 mo after birth or in serum taken 6 wk after birth (sequence 4, G. A. Mulder-Kampinga, unpublished observation). The major variant in $\mathrm{C} 127$ (sequence 5) was not detected in mother M127 either 7 or 0.5 mo before birth.

Clonal HIV-1 populations present around the moment of seroconversion. To determine at which level selection for macrophage-tropic variants occurs, we analyzed biological clones obtained during viremia occurring at the time of seroconversion (Table IV). For each of the three individuals tested, virus populations were extremely homogeneous in V3, already prior to seroconversion, which is in agreement with previous studies $(16,17)$. In one individual $(\mathrm{scB})$, sequence diversification was first shown after more than one year following seroconversion. All virus clones were of the NSI phenotype and had the corresponding genotype. Moreover, cell free infection of MDM indicated that the majority of these clones was highly macrophage tropic.

\section{Discussion}

In the course of asymptomatic HIV-1 infection T cell linetropic SI HIV-1 variants develop in about $50 \%$ of infected people. NSI HIV-1 variants are present during all stages of infection even after the emergence of SI HIV-1 variants. Although both NSI and SI HIV-1 clones can be transmitted (11, 29,30 ), in $95 \%$ of recently infected individuals only NSI HIV-
1 clones can be detected $(5,9)$. Several groups $(16-18)$ have found that the amino acid sequences of the V3 loop of virus populations, present during primary infection in an individual, are very homogeneous and remarkably homologous to sequences characteristic for macrophage-tropic NSI viruses (1315). Clonal analysis of V3 sequences of HIV-1 in documented transmission cases showed that viruses in the recipients had the NSI genotype, even when viruses with SI-type V3 sequences were present in the donor (31). Apparently, during or following transmission strong selective pressures are exerted on this part of the envelope, resulting in positive selection for macrophagetropic HIV-1 clones. In the present study, genotypical and phenotypical analysis of virus populations in donors and recipients of homosexual, parenteral, and vertical transmission cases, isolated around the deduced time of transmission, indeed provided evidence of this assumption. Independent of the route of transmission and the clonal composition of HIV-1 in the donors, in all recipients initially only macrophage-tropic HIV-1 variants were detected.

All HIV-1 clones studied here were lymphocytotropic, but displayed differences in their capacity to infect MT2 cells and MDM. Biological characterization of HIV-1 clones obtained from two homosexual transmission cases pointed to selective establishment of infection by a highly macrophage-tropic clone regardless of the presence of SI variants in the donor. The selection of macrophage-tropic or NSI HIV-1 strains upon sexual transmission has indeed been reported previously (19). In three of five vertical transmission cases most of the mother's variants were macrophage tropic and more than one of these macrophage-tropic variants were detected in their children. In two other cases (102 and 137), however, selection for only one highly macrophage-tropic variant upon transmission was observed. Interestingly, reinterpretation of HIV-1 V3 sequences obtained by Scarlatti et al. (32) from five vertical transmission cases, shows the presence of SI-type V3 sequences in the mothers, while only NSI-type V3 sequences were detected in the corresponding children.

In the present study, in one parenteral (donor $\mathrm{HIV}_{\mathrm{Ams}} 199$ and recipient $\mathrm{ACH} 9012)$ and in three vertical $(114,127$, and 133) transmission cases, more than one of the HIV-1 variants detected in the donors were present in the cognate recipients. There were up to six amino acid differences in V3 sequences between the different SI and NSI HIV-1 clones detected in recipient ACH9012 and four amino acid differences between the two NSI HIV-1 clones in child C133. This variation is too large to assume parallel evolution of HIV-1 clones in both donor and recipient. The NSI HIV-1 clones from the other children (114 and 127) differed by only one amino acid. Sequencing additional regions in the biological clones from these motherchild pairs may show whether the minor variant in the child either has evolved from the major HIV-1 variant in the child or was transmitted simultaneously. Transmission of multiple HIV-1 variants via the vertical route has previously been suggested (33) and may be related to the long exposure time in utero or to the large inoculum to which the newborn may be exposed during delivery.

In donor and recipients as well as within one individual, virus clones with identical V3 loops but different macrophage tropism could be identified. This not only confirms requirements of other envelope regions in macrophage tropism $(14,25,26$, 34-36), but also suggests that the selective pressure is specifically directed at the V3 loop, confirming previous studies (16- 
Table III. Genotype and Phenotype of Biological Clones Obtained from Five Mother-Child Pairs

\begin{tabular}{|c|c|c|c|c|c|c|c|}
\hline \multirow[b]{2}{*}{ Case } & \multirow{2}{*}{$\begin{array}{l}\text { Mo after } \\
\text { delivery }\end{array}$} & \multirow[b]{2}{*}{ No. } & \multirow{2}{*}{$\begin{array}{l}\text { V3 consensus } \\
\text { CTRPNNNTRKSIHIGPGRAFYTTGEIIGDIRQAHC }\end{array}$} & \multirow[b]{2}{*}{$n$} & \multicolumn{3}{|c|}{ Macrophage tropism* } \\
\hline & & & & & G & $\mathbf{H}$ & Classification $^{\ddagger}$ \\
\hline \multirow[t]{7}{*}{ M102 } & -6.5 & 1 & 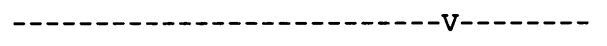 & 9 & $1 / 4$ & $4 / 4$ & ++ \\
\hline & & 2 & - & 1 & $0 / 1$ & $1 / 1$ & + \\
\hline & -0.5 & 1 & 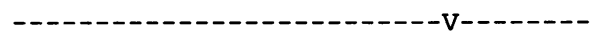 & 7 & $1 / 1$ & $1 / 1$ & +++ \\
\hline & & 2 & - - & 6 & $1 / 2$ & $1 / 2$ & + \\
\hline & & 3 & $----1----Y-$ & 1 & $0 / 1$ & $1 / 1$ & + \\
\hline & & 4 & $-x^{-}$ & 4 & $1 / 1$ & $1 / 1$ & +++ \\
\hline & & 5 & 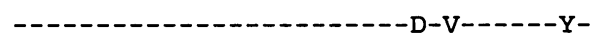 & 1 & $0 / 1$ & $1 / 1$ & + \\
\hline $\mathrm{C} 102$ & 2.5 & 4 & - & 14 & $2 / 4$ & $4 / 4$ & ++ \\
\hline \multirow[t]{5}{*}{ M114 } & -2.0 & 1 & - - - - & 1 & $0 / 1$ & $1 / 1$ & + \\
\hline & & 2 & $---------P-----W----D---N-----$ & 1 & nt & nt & nt \\
\hline & 31.0 & 3 & $-S------R-V------W----D---N-----$ & 2 & $2 / 2$ & $2 / 2$ & +++ \\
\hline & & 1 & $----------P------W----D--------$ & 1 & $1 / 1$ & $1 / 1$ & +++ \\
\hline & & 4 & -S--------UP------W----D---- & 1 & $1 / 1$ & $1 / 1$ & +++ \\
\hline \multirow[t]{9}{*}{ C114 } & 1.0 & 1 & 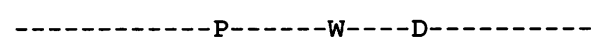 & 14 & $1 / 6$ & $5 / 6$ & + \\
\hline & & 2 & 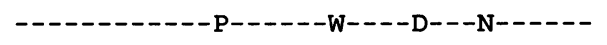 & 1 & $1 / 1$ & $1 / 1$ & +++ \\
\hline & & 5 & 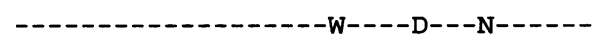 & 1 & $1 / 1$ & $1 / 1$ & +++ \\
\hline & 10.0 & 2 & $----------P-----W----D---N-----$ & 15 & $3 / 3$ & $3 / 3$ & +++ \\
\hline & & 1 & $---------P-----W---D-------$ & 2 & $1 / 1$ & $1 / 1$ & +++ \\
\hline & & 5 & $---------------W---D---N-\cdots$ & 2 & $2 / 2$ & $2 / 2$ & +++ \\
\hline & & 6 & 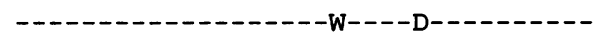 & 2 & $1 / 1$ & $1 / 1$ & +++ \\
\hline & & 7 & $----------S-----W----D---------$ & 2 & $2 / 2$ & $2 / 2$ & +++ \\
\hline & & 8 & ------------SK-----W----D--------- & 1 & $0 / 1$ & $1 / 1$ & + \\
\hline \multirow[t]{5}{*}{ M127 } & -7.0 & 1 & $-\mathrm{I}------\mathrm{K}---\mathrm{TF}---\mathrm{Q}---\mathrm{A}-\mathrm{SN}---\mathrm{N}----\mathrm{Y}-$ & 4 & $1 / 2$ & $1 / 2$ & + \\
\hline & & 2 & $-\mathrm{I}---------\mathrm{TF}---\mathrm{Q}---\mathrm{A}-\mathrm{SN}---\mathrm{N}----\mathrm{Y}-$ & 2 & $0 / 2$ & $1 / 2$ & \pm \\
\hline & -0.5 & 3 & $-\mathrm{I}---------\mathrm{TF}---\mathrm{Q}---\mathrm{A}-\mathrm{SN}-------\mathrm{Y}-$ & 5 & $2 / 4$ & $3 / 4$ & ++ \\
\hline & & 4 & -I----------TF---Q---A-SN-----K--Y- & 3 & $2 / 2$ & $2 / 2$ & +++ \\
\hline & & 2 & -I----------TF---Q---A-SN---N----Y- & 2 & $1 / 2$ & $2 / 2$ & ++ \\
\hline \multirow[t]{3}{*}{ C127 } & 10.5 & 5 & -I----------TF---Q---A-SN--------- & 6 & $5 / 6$ & $6 / 6$ & +++ \\
\hline & & 3 & -I-------- TF---Q-- & 4 & $1 / 2$ & $2 / 2$ & ++ \\
\hline & & 2 & -I--------- TF---Q---A-SN---N----Y- & 1 & $0 / 1$ & $1 / 1$ & + \\
\hline \multirow[t]{5}{*}{ M133 } & -0.5 & 1 & 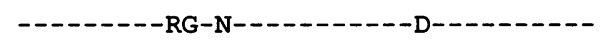 & 1 & nt & nt & nt \\
\hline & & 2 & $--------------K-----D-\cdots----$ & 1 & nt & nt & nt \\
\hline & & 3 & 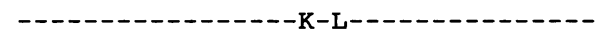 & 1 & nt & nt & nt \\
\hline & 6.0 & 1 & ------ RG-N- - - & 8 & $1 / 2$ & $2 / 2$ & ++ \\
\hline & & 4 & 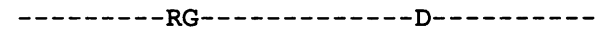 & 1 & $1 / 1$ & $1 / 1$ & +++ \\
\hline \multirow[t]{6}{*}{$\mathrm{C} 133$} & $0.0^{8}$ & 1 & 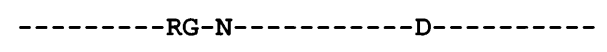 & 1 & $1 / 1$ & $1 / 1$ & +++ \\
\hline & & 2 & $--------------K-----D--------$ & 2 & $1 / 2$ & $2 / 2$ & ++ \\
\hline & 9.5 & 1 & ------- RG-N---------D-- ----- & 1 & $0 / 1$ & $1 / 1$ & + \\
\hline & & 4 & 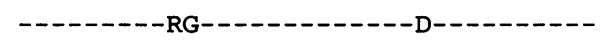 & 1 & $1 / 1$ & $1 / 1$ & +++ \\
\hline & & 2 & -- & 4 & $0 / 1$ & $1 / 1$ & + \\
\hline & & 5 & 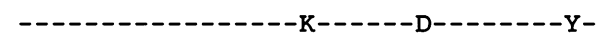 & 1 & $0 / 1$ & $0 / 1$ & - \\
\hline \multirow[t]{11}{*}{ M137 } & -1.5 & 1 & --D-- & 1 & $0 / 1$ & $1 / 1$ & + \\
\hline & & 2 & $--------G--M---K-----------$ & 1 & $0 / 1$ & $1 / 1$ & + \\
\hline & & 3 & - & 1 & $0 / 1$ & $1 / 1$ & + \\
\hline & 9.5 & 4 & 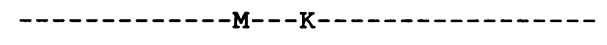 & 1 & $0 / 1$ & $1 / 1$ & + \\
\hline & & 5 & 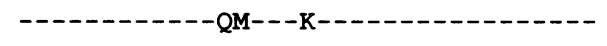 & 6 & $5 / 6$ & $6 / 6$ & +++ \\
\hline & & 6 & 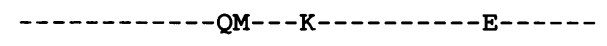 & 1 & $1 / 1$ & $1 / 1$ & +++ \\
\hline & & 7 & $--------G-Q M---K-----------$ & 1 & $1 / 1$ & $1 / 1$ & +++ \\
\hline & & 2 & 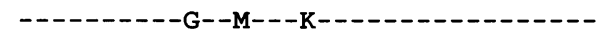 & 1 & $0 / 1$ & $1 / 1$ & + \\
\hline & & 8 & 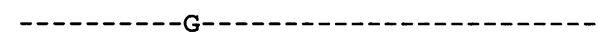 & 7 & $1 / 7$ & $7 / 7$ & ++ \\
\hline & & 3 & 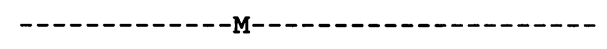 & 1 & $0 / 1$ & $1 / 1$ & + \\
\hline & & 9 & - $-1-1-1-1$ & 5 & $0 / 5$ & $5 / 5$ & + \\
\hline C137 & 12.5 & 5 & 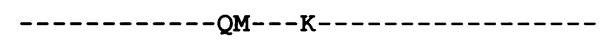 & 6 & $2 / 6$ & $6 / 6$ & ++ \\
\hline
\end{tabular}

M, mother; C, child; No., sequence number; $n$, number of clones. ${ }^{*}$ Number of macrophagetropic clones from the total number of clones tested with that particular V3 loop. Each column represents the results obtained with MDM from 1 blood donor $G, H$. ${ }^{\dagger}$ As defined in the Methods; $n t$, not tested; ${ }^{8}$ cord blood sample. 
Table IV. Genotype and Phenotype of Biological Clones Obtained from Three Patients with a Primary HIV-1 Infection Around the Time of Seroconversion

\begin{tabular}{|c|c|c|c|c|c|c|}
\hline \multirow[b]{2}{*}{ Patient } & \multirow[b]{2}{*}{ D after SC } & \multirow{2}{*}{$\begin{array}{l}\text { V3 consensus } \\
\text { CTRPNNNTRKSIHIGPGRAFYTTGEI IGDIRQAHC }\end{array}$} & \multirow[b]{2}{*}{$n$} & \multicolumn{3}{|c|}{ Macrophage tropism* } \\
\hline & & & & I & $\mathbf{J}$ & Classification $^{*}$ \\
\hline \multirow[t]{8}{*}{ scA } & -8 & $---G-\cdots--V R----Q T--A--A---N-\cdots$ & 14 & $14 / 14$ & $14 / 14$ & +++ \\
\hline & & $----G------V R----Q T--A--A-T-N------$ & 3 & $3 / 3$ & $1 / 3$ & ++ \\
\hline & -2 & $----\mathrm{G}------V R----Q T--A--A---N-----$ & 8 & $8 / 8$ & $8 / 8$ & +++ \\
\hline & 0 & $----G------V R----Q T--A--A---N-----$ & 14 & $14 / 14$ & $14 / 14$ & +++ \\
\hline & 6 & $----G------V R----Q T--A--A---N------$ & 23 & $22 / 23$ & $22 / 23$ & +++ \\
\hline & & $----G------V R----Q T--A--A-T-N-----$ & 1 & $1 / 1$ & $1 / 1$ & +++ \\
\hline & 8 & --- G-----VR----QT--A--A---N----- & 20 & $19 / 20$ & $13 / 20$ & +++ \\
\hline & 62 & $----\mathrm{G}------V R----\mathrm{QT}--\mathrm{A}--\mathrm{A}---\mathrm{N}-\cdots---$ & 2 & $2 / 2$ & $1 / 2$ & ++ \\
\hline \multirow[t]{10}{*}{$\mathrm{scB}$} & -2 & 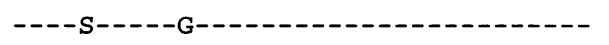 & 4 & $2 / 2$ & nt & +++ \\
\hline & 0 & 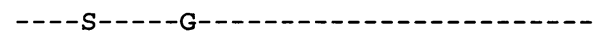 & 4 & $3 / 3$ & nt & +++ \\
\hline & 6 & 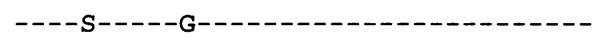 & 3 & $1 / 1$ & nt & +++ \\
\hline & 13 & 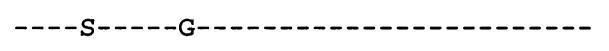 & 1 & nt & nt & nt \\
\hline & 20 & $----S----$ G------- & 1 & $1 / 1$ & nt & +++ \\
\hline & 55 & 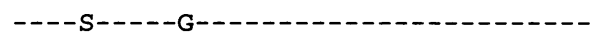 & 2 & $2 / 2$ & nt & +++ \\
\hline & 349 & 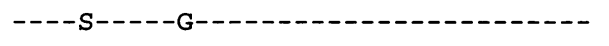 & 3 & $3 / 3$ & nt & +++ \\
\hline & 636 & $---S----G-\cdots--G-----A-------$ & 1 & nt & nt & nt \\
\hline & & 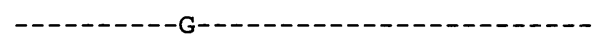 & 1 & $1 / 1$ & nt & +++ \\
\hline & & - & 1 & nt & nt & nt \\
\hline \multirow[t]{4}{*}{$\mathrm{scW}$} & -5 & - - & 6 & $3 / 4$ & $4 / 4$ & +++ \\
\hline & -3 & - - & 7 & $1 / 4$ & $4 / 4$ & ++ \\
\hline & 0 & - - & 22 & $2 / 5$ & $4 / 5$ & ++ \\
\hline & 4 & 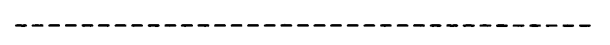 & 6 & $1 / 2$ & $2 / 2$ & ++ \\
\hline
\end{tabular}

$S C$, seroconversion; * Number of macrophagetropic clones from the total number of clones tested with that particular V3 loop. Each column represents the results obtained with MDM from one blood donor $I, J .{ }^{\ddagger}$ As defined in Methods section; nt, not tested.

18), and may not be a reflection of macrophage tropism alone. The selective pressure during transmission favoring macrophage-tropic variants remains to be identified. Hypothetically, selection for macrophage-tropic viruses could already occur in the donor. Differences in the clonal composition of HIV-1 populations in different body compartments have indeed been described $(32,37,38)$. An abundance of macrophage-tropic HIV1 variants in semen or amniotic fluid would indeed facilitate selective transmission of these variants. Currently, however, there are more data in favor of selection during transmission and for selective elimination in the recipient. It has been postulated that macrophages, present in the mucosa and placental tissues, may be the first target cells that HIV-1 encounters (39). This was supported by the observation that HIV-1 infection of uterine cervical explants is only achieved using the macrophagetropic strain HIV-1 Ba-L and is restricted to macrophages present in the explants (40). Here, in three cases with primary HIV-1 infection the clonal macrophage-tropic NSI HIV-1 populations, homogeneous in the V3 loop, were already present before seroconversion. This indeed suggests that selection for macrophagetropic HIV-1 clones may occur already before the induction of the humoral immune response. Moreover, a recent study revealed that in an individual the virus population present during primary infection was homogeneous for a cytotoxic $\mathrm{T}$ lymphocyte (CTL) epitope in V3, which was recognized by a CTL clone of that person (41). This would thus also exclude CTL activity against V3 as the selective pressure in favor of macrophage-tropic variants.
These observations favor selection at the level of the first target cell. The selective elimination of SI variants in recipient ACH9012 of one of the parenteral transmission cases, however, points to selective pressure in favor of macrophage-tropic NSI variants also after establishment of infection, as suggested previously $(10,11)$. This relatively late selection may be directed by immune control. In the asymptomatic phase of HIV-1 infection the presence of high neutralizing antibody titers may allow virus transmission only during direct cell to cell contact, as would occur between macrophages and $\mathrm{T}$ cells during noncognate adhesion or cognate antigen presentation. The observation that peripheral blood $\mathrm{T}$ cells in this phase of infection carry only macrophage-tropic viruses $(7,42)$ is indeed indicative for recent infection of these T cells by progeny from HIV-1 infected macrophages. The emergence of non-macrophage-tropic SI variants in general only at a stage where $\mathrm{CD} 4^{+}$cell numbers are decreased and $T$ cell function is affected (6) indeed suggests that immune control may be responsible for suppression of highly replicating SI HIV-1 variants. This, together with their macrophage tropism, could also explain the incomplete clearance of the SI HIV-1 variants in recipient $\mathrm{HIV}_{\mathrm{Ams}} 127$, who was immune compromised at the moment of infection (20).

This is the first time that both genotype and phenotype of HIV-1 clones has been studied in donors and recipients between whom virus transmission via different routes was documented. Our data show that, although efficiency may be dependent on the route of transmission, both SI and NSI HIV-1 variants can be transmitted. However, in either case a selective expansion 
of macrophage-tropic HIV-1 variants seems to occur in a newly infected individual. Efficiency of transmission and susceptibility for HIV-1 infection may thus be determined by HIV-1 susceptibility of tissue macrophages and the presence of macrophagetropic variants in the inoculum. This finding may have important implications for vaccine development and the understanding of AIDS pathogenesis.

\section{Acknowledgments}

This study was performed as part of the Amsterdam Cohort Studies on AIDS and the Dutch prospective study of HIV-seropositive women and their children. The authors are greatly indebted to all participants for their continuous participation, to Dr. Joep M. A. Lange for providing patient material, to Marijke Roos and colleagues for technical assistance, and to Dr. Thijs Tersmette, Ron Fouchier, and Linde Meyaard for critical reading of the manuscript and continuous helpful discussions.

Supported by a grant (92024) from the Netherlands Ministry of Public Health and by grants $(28-1079,28-1704)$ from the Netherlands Foundation for Preventive Medicine.

\section{References}

1. Asjo, B., J. Albert, A. Karlsson, L. Morfeldt-Månson, G. Biberfeld, K. Lidman, and E. M. Fenyo. 1986. Replicative properties of human immunodeficiency virus from patients with varying severity of HIV infection. Lancet. ii:660662 .

2. Von Briesen, H., W. B. Becker, K. Henco, E. B. Helm, H. R. Gelderblom, H. D. Brede, and H. Rubsamen-Waigmann. 1987. Isolation frequency and growth properties of HIV variants: multiple simultaneous variants in a patient demonstrated by molecular cloning. J. Med. Virol. 23:51-66.

3. Evans, L. A., T. M. McHugh, D. P. Stites, and J. A. Levy. 1987. Differential ability of HIV isolates to productively infect human cells. J. Immunol. 138:34153418.

4. Cheng-Mayer, C., D. Seto, M. Tateno, and J. A. Levy. 1988. Biologic features of HIV-1 that correlate with virulence in the host. Science (Wash. DC). 240:80-82.

5. Tersmette, M., R. E. Y. De Goede, B. J. M. Al, I. N. Winkel, R. A. Gruters, H. T. M. Cuypers, H. G. Huisman, and F. Miedema. 1988. Differential syncytiuminducing capacity of human immunodeficiency virus isolates: frequent detection of syncytium-inducing isolates in patients with acquired immunodeficiency syndrome (AIDS) and AIDS-related complex. J. Virol. 62:2026-2032.

6. Koot, M., I. P. M. Keet, A. H. V. Vos, R. E. Y. De Goede, M. Th. L. Roos, R. A. Coutinho, F. Miedema, P. Th. A. Schellekens, and M. Tersmette. 1993. Prognostic value of human immunodeficiency virus type 1 biological phenotype for rate of $\mathrm{CD}^{+}$cell depletion and progression to AIDS. Ann. Intern. Med. 118:681-688.

7. Schuitemaker, H., N. A. Kootstra, R. E. Y. De Goede, F. De Wolf, F. Miedema, and M. Tersmette. 1991. Monocytotropic human immunodeficiency virus 1 (HIV-1) variants detectable in all stages of HIV infection lack T-cell line tropism and syncytium-inducing ability in primary T-cell culture. J. Virol. 65:356363.

8. Schuitemaker, H., M. Koot, N. A. Kootstra, M. W. Dercksen, R. E. Y. De Goede, R. P. Van Steenwijk, J. M. A. Lange, J. K. M. Eeftink Schattenkerk, F. Miedema, and M. Tersmette. 1992. Biological phenotype of human immunodeficiency virus type 1 clones at different stages of infection: progression of disease is associated with a shift from monocytotropic to T-cell-tropic virus populations. J. Virol. 66:1354-1360.

9. Keet, I. P. M., P. Krijnen, M. Koot, J. M. A. Lange, F. Miedema, J. Goudsmit, and R. A. Coutinho. 1993. Predictors of rapid progression to AIDS in HIV-1 seroconverters. Aids (Phila.). 7:51-57.

10. Groenink, M., R. A. M. Fouchier, R. E. Y. De Goede, F. De Wolf, H. T. M. Cuypers, R. A. Gruters, H. G. Huisman, and M. Tersmette. 1991 Phenotypical heterogeneity in a panel of infectious molecular HIV-1 clones derived from a single individual. J. Virol. 65:1968-1975.

11. Roos, M. Th. L., J. M. A. Lange, R. E. Y. De Goede, R. A. Coutinho, P. Th. A. Schellekens, F. Miedema, and M. Tersmette. 1992. Virus phenotype and immune response in primary human immunodeficiency virus type 1 (HIV-1) infection. J. Infect. Dis. 165:427-432.

12. Baur, A., N. Schwarz, S. Ellinger, K. Korn, T. Harrer, K. Mang, and G. Jahn. 1989. Continuous clearance of HIV in a vertically infected child. Lancet. ii: 1045 .

13. De Jong, J. J., J. Goudsmit, W. Keulen, B. Klaver, W. Krone, M. Tersmette, and T. De Ronde. 1992. Human immunodeficiency viruses type-1 chimeric for the envelope V3 domain are distinct in syncytium formation and replication capacity. J. Virol. 66:757-765.

14. Fouchier, R. A. M., M. Groenink, N. A. Kootstra, M. Tersmette, H. G. Huisman, F. Miedema, and H. Schuitemaker. 1992. Phenotype-associated sequence variation in the third variable domain of the human immunodeficiency virus type 1 gp120 molecule. J. Virol. 66:3183-3187.

15. Chesebro, B., K. Wehrly, J. Nishio, and S. Perryman. 1992. Macrophagetropic Human immunodeficiency virus isolates from different patients exhibit unusual V3 envelope sequence homogeneity in comparison with $\mathrm{T}$ cell-tropic isolates: definition of critical amino acids involved in cell tropism. J. Virol. 66:6547-6554.

16. Zhang, L. Q., P. MacKenzie, A. Cleland, E. C. Holmes, A. J. LeighBrown, and P. Simmonds. 1993. Selection for specific sequences in the external envelope protein of HIV-1 upon primary infection. J. Virol. 67:3345-3356.

17. McNearney, T., Z. Hornickova, R. Markham, A. Birdwell, M. Arens, A. Saah, and L. Ratner. 1992. Relationship of human immunodeficiency virus type 1 sequence heterogeneity to stage of disease. Proc. Natl. Acad. Sci. USA. 89:1024710251.

18. Kuiken, C. L., G. Zwart, E. Baan, R. A. Coutinho, J. A. R. van den Hoek, and J. Goudsmit. 1993. Increasing antigenic and genetic diversity of the V3 variable domain of the human immunodeficiency virus envelope protein in the course of the AIDS epidemic. Proc. Natl. Acad. Sci. USA. 90:9061-9065.

19. Zhu, T., H. Mo, N. Wang, D. S. Nam, Y. Cao, R. A. Koup, and D. D. Ho. 1993. Genotypic and phenotypic characterization of HIV-1 in patients with primary infection. Science (Wash. DC). 261:1179-1181.

20. Lange, J. M. A., C. A. B. Boucher, C. E. M. Hollak, E. H. H. Wiltink, P. Reiss, E. A. Van Royen, M. Th. L. Roos, S. A. Danner, and J. Goudsmit. 1990. Failure of zidovudine prophylaxis after accidental exposure to HIV-1. N. Engl. J. Med. 322:1375-1377.

21. Boom, R., C. J. A. Sol, M. M. M. Salimans, C. L. Jansen, P. M. E. Wertheim-van Dillen, and J. Van der Noordaa. 1991. A rapid and simple method for purification of nucleic acids. J. Clin. Microbiol. 28:495-503.

22. Simmonds, P., P. Balfe, C. A. Ludlam, J. O. Bishop, and A. J. L. Brown. 1990. Analysis of sequence diversity in hypervariable regions of the external glycoprotein of human immunodeficiency virus type 1. J. Virol. 64:5840-5850.

23. Fouchier, R. A. M., M. Brouwer, N. A. Kootstra, J. G. Huisman, F. Miedema, and H. Schuitemaker. 1994. Macrophage tropism of human immunodeficiency virus type 1 is determined by viral and cellular factors at multiple steps of the replication cycle. J. Clin. Invest. 94:1806-1814.

24. Schuitemaker, H., M. Groenink, L. Meyaard, N. A. Kootstra, R. A. M. Fouchier, R. A. Gruters, H. G. Huisman, M. Tersmette, and F. Miedema. 1993. Early replication steps but not cell-type specific signalling of the viral long terminal repeat determine HIV-1 monocytotropism. Aids Res. Hum. Retroviruses. 9:669-675.

25. O'Brien, W. A., Y. Koyanagi, A. Namazie, J. Q. Zhao, A. Diagne, K. Idler, J. A. Zack, and I. S. Y. Chen. 1990. HIV-1 tropism for mononuclear phagocytes can be determined by regions of gp120 outside the CD4-binding domain. Nature (Lond.). 348:69-73.

26. Shioda, T., J. A. Levy, and C. Cheng-Mayer. 1991. Macrophage and T cell-line tropisms of HIV-1 are determined by specific regions of the envelope gp120 gene. Nature (Lond.). 349:167-169.

27. Bruisten, S. M., M. H. G. M. Koppelman, C. L. Van der Poel, and J. G. Huisman. 1991. Enhanced detection of HIV-1 sequences using PCR and a liquid hybridization technique. Vox Sang. 61:24-29.

28. Mulder-Kampinga, G. A., C. Kuiken, J. Dekker, H. J. Scherpbier, K. Boer, and J. Goudsmit. 1993. Genomic human immunodeficiency virus type 1 RNA variation in mother and child following intra-uterine virus transmission. J. Gen. Virol. 74:1747-1756.

29. Clark, J. C., M. S. Saag, W. D. Decker, S. Campbell-Hill, J. L. Roberson, P. J. Veldkamp, J. C. Kappes, B. H. Hahn, and G. M. Shaw. 1991. High titers of cytopathic virus in plasma of patients with symptomatic primary HIV-1 infection. N. Engl. J. Med. 324:954-960.

30. Nielsen, C., C. Pedersen, J. D. Lundrgen, and J. Gerstof. 1993. Biological properties of HIV-isolates in primary HIV-infection: consequences for the subsequent course of infection. Aids (Phila.). 7:1035-1040.

31. Wolfs, T. F. W., G. Zwart, M. Bakker, and J. Goudsmit. 1992. HIV-1 genomic RNA diversification following sexual and parenteral virus transmission. Virology. 189:103-110.

32. Scarlatti, G., T. Leitner, E. Halapi, J. Wahlberg, P. Marchisio, M. A Clerici-Schoeller, H. Wigzell, E. M. Fenyö, J. Albert, M. Uhlén, and P. Rossi. 1993. Comparison of variable region 3 sequences of human immunodeficiency virus type 1 from infected children with the RNA and DNA sequences of the virus populations of their mothers. Proc. Natl. Acad. Sci. USA. 90:1721-1725.

33. Lamers, S. L., J. W. Sleasman, J. X. She, K. A. Barrie, S. M. Pomeroy, D. J. Barrett, and M. M. Goodenow. 1994. Persistence of multiple maternal genotypes of human immunodeficiency virus type 1 in infants infected by vertical transmission. J. Clin. Invest. 93:380-390.

34. McNearney, T., P. Westervelt, B. J. Thielan, D. B. Trowbridge, J. Garcia, R. Whittier, and L. Ratner. 1990. Limited sequence heterogeneity among biologically distinct human immunodeficiency virus type 1 isolates from individuals 
involved in a clustered infectious outbreak. Proc. Natl. Acad. Sci. USA. 87:19171921.

35. Groenink, M. A. C. Andeweg, R. A. M. Fouchier, S. Broersen, R. C. M. Van der Jagt, H. Schuitemaker, R. E. Y. De Goede, M. L. Bosch, H. G. Huisman, and $M$. Tersmette. 1992. Phenotype associated env gene variation among eight related human immunodeficiency virus type 1 clones: evidence for in vivo recombination and determinants of cytotropism outside the V3 domain. J. Virol. 66:6175-6180.

36. Westervelt, P., H. E. Gendelman, and L. Ratner. 1991. Identification of a determinant within the human immunodeficiency virus 1 surface envelope glycoprotein critical for productive infection of primary monocytes. Proc. Natl. Acad. Sci. USA. 88:3097-3101.

37. Simmonds, P., L. Q. Zhang, F. McOmish, P. Balfe, C. A. Ludlam, and A. J. L. Brown. 1991. Discontinuous sequence change of human immunodeficiency virus (HIV) type 1 env sequences in plasma viral and lymphocyte-associated proviral populations in vivo: Implications for models of HIV pathogenesis. J. Virol. 65:6266-6276.
38. Epstein, L. G., C. Kuiken, B. M. Blumberg, S. Hartman, L. R. Sharer, M. Clement, and J. Goudsmit. 1991. HIV-1 V3 domain variation in brain and spleen of children with AIDS: Tissue-specific evolution within host-determined quasispecies. Virology. 180:583-590.

39. Braathen, L. R., G. Ramirez, R. O. F. Kunze, and H. Gelderblom. 1987. Langerhans cells as primary target cells for HIV infection. Lancet. ii 1094.

40. Griffin, G. E. 1993. HIV infection of human intestinal and cervical epithelial cultures in vitro. Second International Workshop on HIV and Cells of Macrophage Lineage 21. (Abstr.).

41. Safrit, J. T., C. Andrews, A. Lee, and R. A. Koup. 1994. Isolation and characterisation of three HLA-B27 restricted cytotoxic T lymphocyte clones specific for the third variable region of HIV-1 gp120. J. Cell. Biochem. s18B:J329.(Abstr.).

42. Massari, F. E., G. Poli, S. M. Schnittman, M. C. Psallidopoulos, V. Davey, and A. S. Fauci. 1990. In vivo T lymphocyte origin of macrophage-tropic strains of HIV. Role of monocytes during in vitro isolation and in vivo infection. $J$. Immunol. 144:4628-4632. 